\title{
Article \\ Study on the Influence of a Soft Soil Interlayer on Spatially Varying Ground Motions
}

\author{
Erlei Yao ${ }^{1}$, Weichao $\mathrm{Li}^{1}$, Yu Miao ${ }^{2}$, Lin Ye ${ }^{2}$ and Zhaowei Yang ${ }^{1, *}$ \\ 1 Key Laboratory of Geotechnical Mechanics and Engineering of the Ministry of Water Resources, \\ Changjiang River Scientific Research Institute, Wuhan 430010, China; yaoel@mail.crsri.cn (E.Y.); \\ liwc0905@mail.crsri.cn (W.L.) \\ 2 School of Civil and Hydraulic Engineering, Huazhong University of Science and Technology, Wuhan 430074, \\ China; miaoyu@hust.edu.cn (Y.M.); yelin19@hust.edu.cn (L.Y.) \\ * Correspondence: yangzw@whu.edu.cn
}

Citation: Yao, E.; Li, W.; Miao, Y.; Ye, L.; Yang, Z. Study on the Influence of a Soft Soil Interlayer on Spatially Varying Ground Motions. Appl. Sci. 2022, 12, 1322. https://doi.org/ 10.3390/app12031322

Academic Editor: Chiara Bedon

Received: 30 December 2021

Accepted: 24 January 2022

Published: 26 January 2022

Publisher's Note: MDPI stays neutral with regard to jurisdictional claims in published maps and institutional affiliations.

Copyright: (c) 2022 by the authors. Licensee MDPI, Basel, Switzerland. This article is an open access article distributed under the terms and conditions of the Creative Commons Attribution (CC BY) license (https:// creativecommons.org/licenses/by/ $4.0 /)$.

\begin{abstract}
The existence of local soft interlayer can significantly amplify or attenuate the ground motion and thus might influence the lagged spatial coherency between spatially varying earthquake ground motions. A target site with a local soft interlayer was assumed first, and then two numerical examples were set. In example 1, linear soil behavior was considered and a large amount of quasistationary spatially varying earthquake ground motions were generated by combining the onedimensional wave propagation theory and the classical spectral representation method. The influence regularity of varying shear wave velocity, buried depth, and thickness of the soft interlayer on the characteristics of lagged spatial coherency was investigated. In example 2, non-linear soil behavior was taken into account and fully non-stationary spatially varying earthquake ground motions were thus generated by using time-varying transfer function and spectral representation method. An overall evaluation was carried out to shed light on the differences of characteristics of spatial coherency between non-linear soil and linear soil cases. It showed that: (i) As the shear wave velocity of interlayer declines and as the buried depth and thickness increase, remarkable reduction of spatial coherency showed up; (ii) the reduction of lagged spatial coherency caused by varying buried depth may be more inclined to concentrate in the lower frequency range; (iii) the non-linear soil behavior can cause greater further reduction of lagged spatial coherency in comparison with linear soil behavior, especially in the higher frequency range; (iv) the troughs of lagged spatial coherency curve tend to be located in the variation range of vibration frequency of time-varying spectral ratio.
\end{abstract}

Keywords: soft soil interlayer; lagged coherency; spatially varying ground motions; one-dimensional wave propagation theory; time-varying transfer function; non-linear soil behavior

\section{Introduction}

The spatial variation of ground motions is moving researchers and engineers' focus toward the seismic response characteristics of large-scale or extended structures [1-11] and engineering site [12-14] under spatially varying earthquake ground motions (SVEGMs). However, the empirical analysis of SVEGMs requires the availability of spatially dense strong motion arrays, which are indeed rare even on a worldwide scale. Therefore, artificial simulation of SVEGMs is now widely employed and many simulation methods have been developed [15-25].

In addition, spatial coherency function measures the similarity of the motions at two different locations [26] and indicates the degree to which the data recorded at the two stations are related. A lot of coherency models or relevant studies [27-32] have been reported to facilitate the generation of SVEGMs based on theoretical derivation or measured spatial ground motions at dense seismographic arrays, in which specific site conditions (e.g., topography and soft soil interlayer) were not considered. Therefore, a lot of studies were performed on the influence of site conditions on the spatial coherency [26,33-37]. 
However, in general, these studies were on the basis that the soil property was linear and/or the shear modulus of soil layers were regularly increasing as depth, and underlying soft soil interlayer or non-linear soil behavior was not taken into account.

On one hand, besides the topography [38-40], the existence of soft interlayer can also change the propagation path of wave from bedrock to surface in comparison with corresponding regularly and horizontally stratified site and can significantly amplify or attenuate the ground motion [41-43]. On the other hand, it has long been recognized that, during strong ground motions, non-linear soil behavior tends to reduce site amplification at high frequencies due to the increase of damping and also tends to shift resonance frequencies of site toward lower frequencies due to the degradation of shear modulus [44-50]. In the decay stage of ground motion, the shear modulus and damping of soil may recover and thus the amplification and filtering effects may recover as well [51,52]. Taking all abovementioned into consideration, the nonlinear soil behavior during earthquake may considerably change the amplification and filtering effect of soil on ground motion and thus the soft interlayer that may reflect highly non-linearity might possess non-negligible influence on the spatial coherency between SVEGMs.

Therefore, a site with local soft soil interlayer was assumed first, and two numerical examples were set in the present paper to: (i) Study the influence regularity of the properties of soft soil interlayer itself on the lagged spatial coherency; and (ii) demonstrate the difference of spatial coherency characteristics between linear elastic soil and non-linear soil cases. In example 1 (linear soil case), by combining the 1D wave propagation theory with classical spectral representation method (SRM), numerous quasi-stationary SVEGMs in horizontal out-of-plane, horizontal in-plane, and vertical in-plane directions were simulated for the target site, where varying shear wave velocity, buried depth, and thickness of the soft interlayer were considered. In example 2 (non-linear soil case), fully non-stationary SVEGMs were generated in those three directions, into which the spectral non-stationarity of ground motion caused by non-linear soil behavior was introduced. Besides the shear wave velocity, buried depth, and thickness of the soft interlayer, varying PGA of input motion was also considered in this example. Then mean lagged spatial coherency between SVEGMs under each circumstance above mentioned was estimated, and a series of comparisons were conducted.

\section{Theoretical Basis}

\subsection{One-Dimensional Wave Propagation Theory}

In the 1D wave propagation theory proposed by Wolf [53], it is assumed that the incoming seismic waves that propagate into the bedrock with an angle consist of out-ofplane SH wave or in-plane combined P-and SV-waves. For each soil layer, the out-of-plane and in-plane dynamic stiffness matrices can be established independently. Then, based on the relation between shear stresses and displacements on interfaces between soil layers and by assembling the dynamic stiffness matrices of soil layers and bedrock, the dynamic equilibrium equation of the site in frequency domain can be expressed as

$$
\left[S_{S H}\right]\left\{u_{S H}\right\}=\left\{P_{S H}\right\} \text { for out-of-plane wave }
$$

and

$$
\left[S_{P-S V}\right]\left\{u_{P-S V}\right\}=\left\{P_{P-S V}\right\} \text { for in-plane waves, }
$$

where $\left[S_{S H}\right]$ and $\left[S_{P-S V}\right]$ are the out-of-plane and in-plane dynamic stiffness matrices of site, respectively; $\left\{u_{S H}\right\}$ and $\left\{P_{S H}\right\}$ are the out-of-plane displacements and load vectors for the incident $\mathrm{SH}$ wave, respectively; $\left\{u_{P-S V}\right\}$ and $\left\{P_{P-S V}\right\}$ are the in-plane displacement and load vectors for the combined P-and SV-waves, respectively. The ratio between the displacement at certain soil layer and that at bedrock site defines the transfer function $H(\omega)$, which can be derived by solving Equations (1) or (2). 
Taking a single soil layer resting on a half-space with incident $\mathrm{SH}$ wave as an example, the transfer function for $\mathrm{SH}$ wave can be expressed as:

$$
\begin{gathered}
H(i \omega)=\frac{1}{\cos k t^{L} d+\frac{i}{p} \sin k t^{L} d}, \\
p=\frac{t^{R} G^{* R}}{t^{L} G^{* L}}, \\
G^{* L}=G^{L}\left(1+2 \zeta^{L} i\right) \text { and } G^{* R}=G^{R}\left(1+2 \zeta^{R} i\right),
\end{gathered}
$$

in which $k$ denotes the wave number; $t^{R}$ or $t^{L}$ is a function of incident angle; $G$ is the shear modulus; $d$ is the thickness of soil layer; superscript $R$ and $L$ denote bedrock and soil layer, respectively; $\zeta$ is the damping ratio; $i=\sqrt{-1}$.

\subsection{Time-Varying Transfer Function}

During earthquake, soil properties (e.g., shear modulus and damping ratio) may be varying with time, which may influence the transfer function of the site and thus the surface ground motion. To incorporate the influence of non-linear soil behavior into the simulation of fully non-stationary SVEGMs and based on the assumption that the soil property is linear at each minute time interval, the authors obtained time-varying soil properties by using a numerical site response analysis and substituted time-varying shear modulus and damping ratio data into the classical transfer function, and then time-varying transfer function was established (Detailed information can be found in Refs. [51,52]):

$$
H(i \omega, t)=\frac{1}{\cos k t^{L} d+\frac{i}{p(t)} \sin k t^{L} d}
$$

\subsection{Simulation of Fully Non-Stationary SVEGMs}

Based on the time-varying transfer function abovementioned, the evolutionary auto/crosspower spectral density function (PSDF) on site surface can be derived by

$$
\begin{gathered}
S_{j j}(\omega, t)=[a(t)]^{2}\left|H_{j}(i \omega, t)\right|^{2} S_{g}(\omega) \quad j=1,2, \ldots n, \\
\text { and } S_{j k}(i \omega, t)=[a(t)]^{2} H_{j}(i \omega, t) H_{k}^{\Theta}(i \omega, t) S_{g}(\omega) \gamma_{j^{\prime} k^{\prime}}\left(d_{j^{\prime} k^{\prime}}, i \omega\right) \quad j, k=1,2, \ldots n,
\end{gathered}
$$

respectively, where $H_{j}$ and $H_{k}$ are the transfer functions at simulation points $j$ and $k$, respectively; $a(t)$ is a modulating function in time; superscript " $\Theta$ " denotes complex conjugate; $S_{g}(\omega)$ is the ground motion PSDF at the base rock; $\gamma_{j^{\prime} k^{\prime}}\left(d_{j^{\prime} k^{\prime}}, i \omega\right)$ is the spatial coherency function of spatial ground motions at the base rock which is related to the separation distance $d_{j^{\prime} k^{\prime}}$ and $\omega$.

Then, power spectral density matrix (PSDM) can be formed. By using the classical simulation method of SVEGMs proposed by Deodatis [18] in combination with the root decomposition $[21,54]$ of the PSDM, fully non-stationary SVEGMs can then be generated by

$$
\begin{gathered}
f_{j}(t)=2 \sum_{x=1}^{n} \sum_{y=1}^{N}\left|U_{j x}\left(\omega_{y}, t\right)\right| \sqrt{\Delta \omega} \cos \left[\omega_{y} t-\theta_{j x}\left(\omega_{y}, t\right)+\Phi_{x y}\right] \quad j=1,2, \ldots n \\
\omega_{y}=y \Delta \omega \quad y=1,2, \ldots N \\
\Delta \omega=\frac{\omega_{u}}{N} \\
\theta_{j x}\left(\omega_{y}, t\right)=\tan ^{-1}\left(\frac{\operatorname{Im}\left[U_{j x}\left(\omega_{y}, t\right)\right]}{\operatorname{Re}\left[U_{j x}\left(\omega_{y}, t\right)\right]}\right)
\end{gathered}
$$


With $\Delta \omega$ denoting the bandwidth and $N$ the number of frequency interval. $\omega_{u}$ represents an upper cut-off frequency beyond which the elements of the PSDM may be assumed to be zero for any time instant. $U_{j x}\left(\omega_{y}, t\right)$ is an element of the matrix obtained through the decomposition of PSDM. $\Phi_{x y}$ is a random phase angle uniformly distributed in $[0,2 \pi]$.

In summary, for linear soil case, 1D wave propagation theory was directly used to conduct the study, while for non-linear soil case the flow of the methodology is as follows:

(1) Obtain the time-varying trend of fundamental properties (e.g., shear modulus) of soils in the target site by using a numerical site response based on FE code ABAQUS;

(2) Obtain the time-varying transfer function of the target site based on above mentioned time-varying trend of fundamental properties of soils;

(3) Obtain power spectral density for surface ground motions by using time-varying transfer function and prescribed power spectral density model for bedrock and artificially simulate surface spatially varying earthquake ground motions;

(4) Estimate mean coherency loss between generated spatially varying earthquake ground motions.

Note that the simulation of quasi-stationary SVEGMs is a special case of that of fully non-stationary SVEGMs, and quasi-stationary SVEGMs can be derived by combining the transfer function that is invariable with time with the classical SRM.

\section{Numerical Example 1: Linear Soil Behavior}

\subsection{Setup of the Numerical Example}

First, a regular site without soft interlayer is set as a control (see Figure 1a), and the target site in which a soft soil layer lies beneath site $\mathrm{k}$ is then set up as shown in Figure $1 \mathrm{~b}$. In this figure, $H$ and $C s$ denote the thickness and shear wave velocity of soil layer; $\mu$ is the Poisson's ratio; $D^{S I}, H^{S I}$, and $C S^{S I}$ denote the buried depth, thickness, and shear wave velocity of the soft interlayer, respectively; $\zeta$ denotes initial damping and is set to $5 \%$. Because linear soil behavior (i.e., the parameters of soil are constant) is considered in this example, quasi-stationary SVEGMs at sites $\mathrm{j}$ and $\mathrm{k}$ are generated based on the method introduced in Section 2. The motions on the bedrock are assumed to have the same intensity and frequency contents, and the filtered Tajimi-Kanai model [55] is utilized to describe the PSDF on the bedrock:

$$
S_{g}(\omega)=\frac{\omega^{4}}{\left(\omega_{f}^{2}-\omega^{2}\right)^{2}+\left(2 \omega_{f} \omega \zeta_{f}\right)^{2}} \times \frac{\omega_{g}^{4}+4 \zeta_{g}^{2} \omega_{g}^{2} \omega^{2}}{\left(\omega_{g}^{2}-\omega^{2}\right)^{2}+4 \zeta_{g}^{2} \omega_{g}^{2} \omega^{2}} S_{0}
$$

where $\omega_{g}$ and $\zeta_{g}$ are the central frequency and damping ratio of the Tajimi-Kanai PSDF, $\omega_{f}$ and $\zeta_{f}$ are the central frequency and damping ratio of the high pass filter; $S_{0}$ is the scaling factor and can be calculated by [56]

$$
S_{0}=\frac{a_{\max }^{2}}{\gamma^{2}\left[\pi \omega_{g}\left(2 \zeta_{g}+\frac{1}{2 \zeta_{g}}\right)\right]}
$$

where $a_{\text {max }}$ denotes the PGA value and is set to $0.3 \mathrm{~g}$ in this example; $\gamma$ is the peak factor. In this study, $\gamma=2.8, \omega_{g}=10 \pi \mathrm{rad} / \mathrm{s}, \zeta_{g}=0.6, \omega_{f}=0.5 \pi$, and $\zeta_{f}=0.6$ are set. Note that the amplitude of the vertical motion is set to $2 / 3$ of that of the horizontal component. It is also notable that the motion on the base rock is assumed to have the same intensity and frequency contents. 

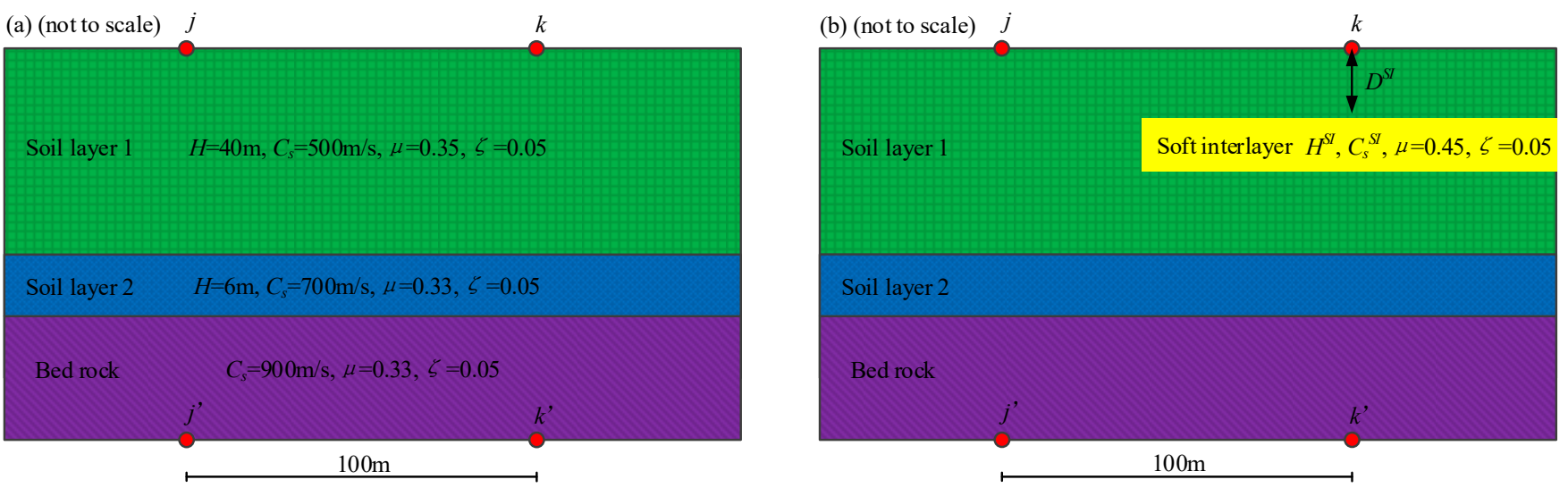

Figure 1. Site conditions for: (a) The regular site without soft interlayer; (b) the site with soft interlayer.

The spatial coherency between the motions at points $j^{\prime}$ and $k^{\prime}$ (bedrock motions) is described by the Sobczyk model [57]:

$$
\gamma_{j^{\prime} k^{\prime}}(i \omega)=\exp \left(-\beta \omega d_{j^{\prime} k^{\prime}}^{2} / V e\right) \cdot \exp \left(-i \omega d_{j^{\prime} k^{\prime}} \cos \alpha / V e\right) \quad j^{\prime}, k^{\prime}=1^{\prime}, 2^{\prime}, 3^{\prime}
$$

where $\beta=0.0005$ is used herein, which indicates highly correlated motions; $\alpha$ is the incident angle of the incoming wave to the site; Ve is the apparent velocity which is related to the bedrock property and the specified incident angle.

The Jennings window is employed to model the temporal non-stationarity of simulated ground motions, which has the following form:

$$
a(t)=\left\{\begin{array}{cl}
\left(t / t_{1}\right)^{2} & t<t_{1} \\
1 & t_{1} \leq t<t_{2} \\
\exp \left[-c\left(t-t_{2}\right)\right] & t \geq t_{2}
\end{array}\right.
$$

in which $t_{1}, t_{2}$, and $c$ are set to 6,10 , and 0.5 , respectively. The sampling frequency and upper cut-off frequency are set to $100 \mathrm{~Hz}$ and $25 \mathrm{~Hz}$, respectively, and the duration is set to $20 \mathrm{~s}$. The same set of random phase angles are used to simulate horizontal and vertical motions. Moreover, to study the influence regularity of the properties of soft interlayer itself on lagged spatial coherency, varying shear wave velocity, buried depth, and thickness of the soft interlayer are considered as shown in Table 1. Note that, in the case with thickness, $D^{S I}$ is also varying corresponding to $H^{S I}$ to assure the center line of soft interlayer is fixed. It is also noteworthy that the incident angle of horizontal in-plane motion is calculated according to that of vertical motion and the wave velocity ratio between shear wave and compression wave, which is demanded in 1D wave propagation theory [53]. For each case, 1000 simulations are performed to calculate the mean lagged spatial coherencies between ground motions at sites $\mathrm{j}$ and $\mathrm{k}$, and detailed information about the calculation can be found in Ref. [26].

Table 1. Study cases performed in example 1.

\begin{tabular}{cccc}
\hline Item & $\begin{array}{c}\text { The Case with Shear } \\
\text { Wave Velocity }\end{array}$ & $\begin{array}{c}\text { The Case with } \\
\text { Buried Depth }\end{array}$ & $\begin{array}{c}\text { The Case with } \\
\text { Thickness }\end{array}$ \\
\hline$C H^{S I}$ & $5 \mathrm{~m}$ & $5 \mathrm{~m}$ & $1 / 5 / 10 \mathrm{~m}$ \\
$D^{S I}$ & $5 \mathrm{~m}$ & $5 / 15 / 25 \mathrm{~m}$ & $7 / 5 / 2.5 \mathrm{~m}$ \\
\hline PGA & & $0.3 \mathrm{~g}$ \\
Incident angle & $60^{\circ}$ for SH-wave, $75.4^{\circ}$ for SV-wave, and $60^{\circ}$ for P-wave \\
\hline
\end{tabular}




\subsection{Results and Discussion}

To illustrate, for the case with $C s^{S I}=100 \mathrm{~m} / \mathrm{s}, D^{S I}=5 \mathrm{~m}$, and $H^{S I}=5 \mathrm{~m}$, the transfer functions and one set of SVEGMs samples are plotted in Figures 2 and 3, respectively. Although the same set of random phase angles were used to simulate horizontal and vertical motions, different characteristics are shown, which is attributed to the difference between vibration modes in horizontal and vertical directions.
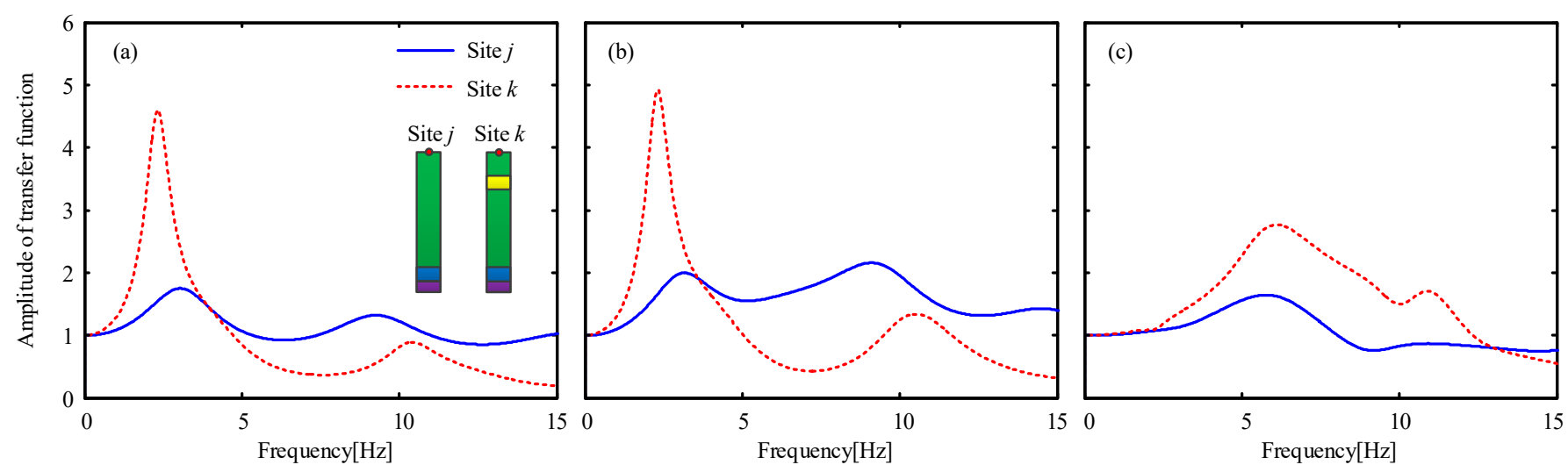

Figure 2. Transfer functions at sites $\mathrm{j}$ and $\mathrm{k}$ for: (a) horizontal out-of-plane motion; (b) horizontal in-plane motion; and (c) vertical in-plane motion when $C_{S}{ }^{S I}=100 \mathrm{~m} / \mathrm{s}, D^{S I}=5 \mathrm{~m}$, and $H^{S I}=5 \mathrm{~m}$.
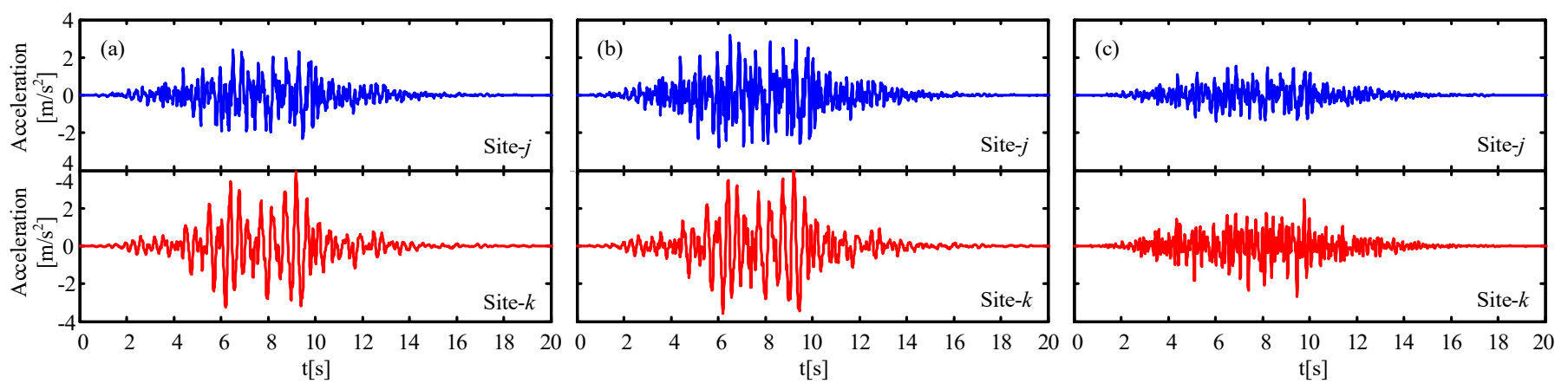

Figure 3. Simulated ground motions for: (a) horizontal out-of-plane motion; (b) horizontal in-plane motion; and (c) vertical in-plane motion $C_{S}{ }^{S I}=100 \mathrm{~m} / \mathrm{s}, D^{S I}=5 \mathrm{~m}$, and $H^{S I}=5 \mathrm{~m}$.

Figure 4 gives the mean lagged spatial coherency between surface horizontal out-ofplane motions under different shear velocities, buried depths, and thicknesses of the soft interlayer, where the corresponding modulus of spectral ratio between sites $\mathrm{j}$ and $\mathrm{k}$ are also given (here, spectral ratio is defined as the ratio between the transfer functions at sites $j$ and $\mathrm{k}$ ). The mean lagged spatial coherency between bedrock motions and the one for the regular site without soft interlayer are shown in the same figure as well. Figures 5 and 6 present the results for horizontal and vertical in-plane motions, respectively.

Comparing the spatial coherency functions on the site with soft interlayer (Figure 1b) with those on the regular site (Figure 1a), it can be found that the existence of a soft interlayer can further reduce the spatial coherency. Besides, the spatial coherency functions decrease as the shear wave velocity of the soft interlayer declines; by contrast, higher buried depth and thickness can bring about lower spatial coherency. This is because that the decreasing shear wave velocity or increasing buried depth and thickness of soft interlayer can significantly differ the transfer function at site $\mathrm{k}$ from that at site $\mathrm{j}$, i.e., changing the amplitude and vibration frequencies, which can be justified by observing the spectral ratio (see Figures 4-6) and can bring about obvious differences between the frequency contents of ground motions at sites $\mathrm{j}$ and $\mathrm{k}$. Therefore, the spatial coherency tends to be lower. 

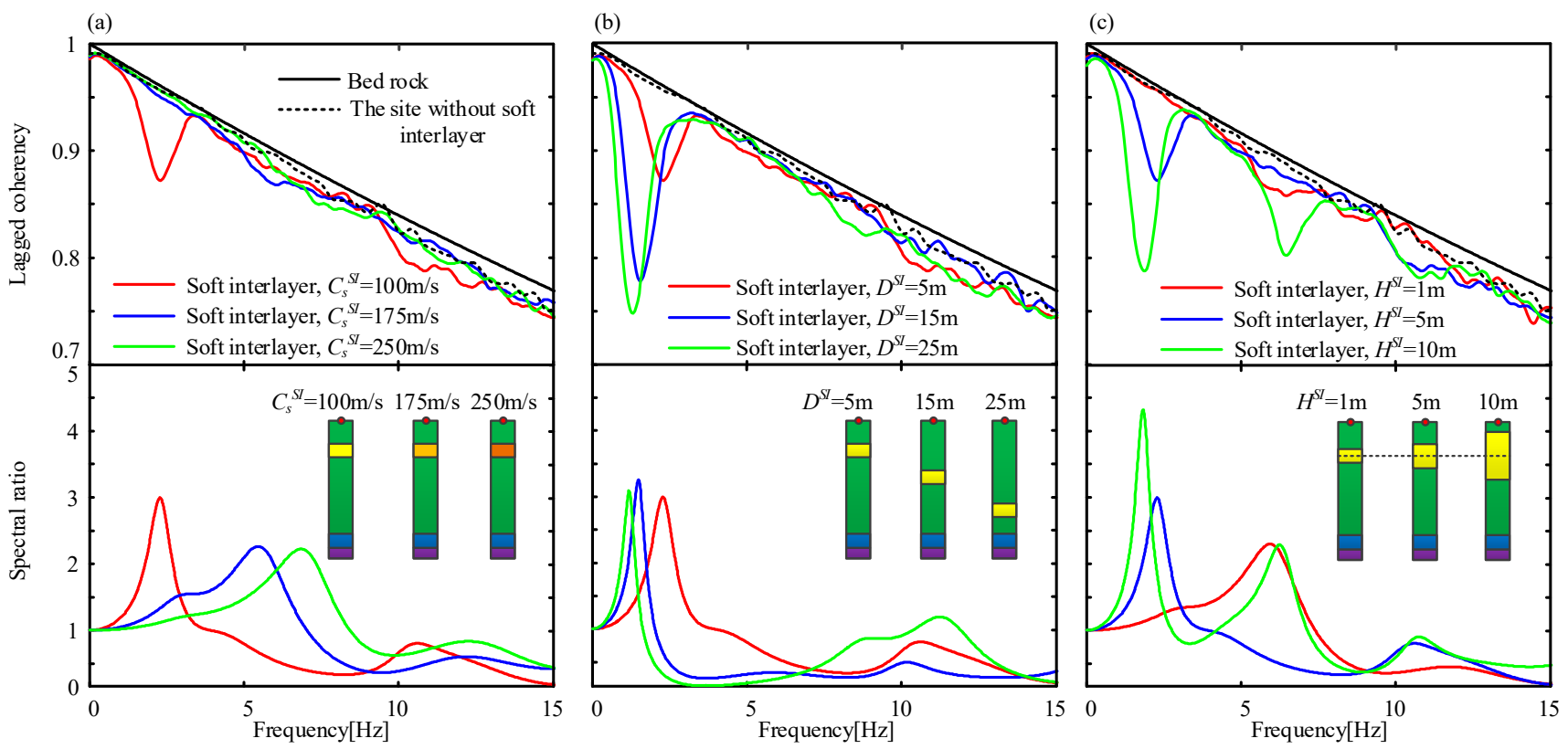

Figure 4. Mean lagged coherency between horizontal out-of-plane motions and corresponding spectral ratios for varying (a) shear wave velocity; (b) buried depth; and (c) thickness of interlayer.
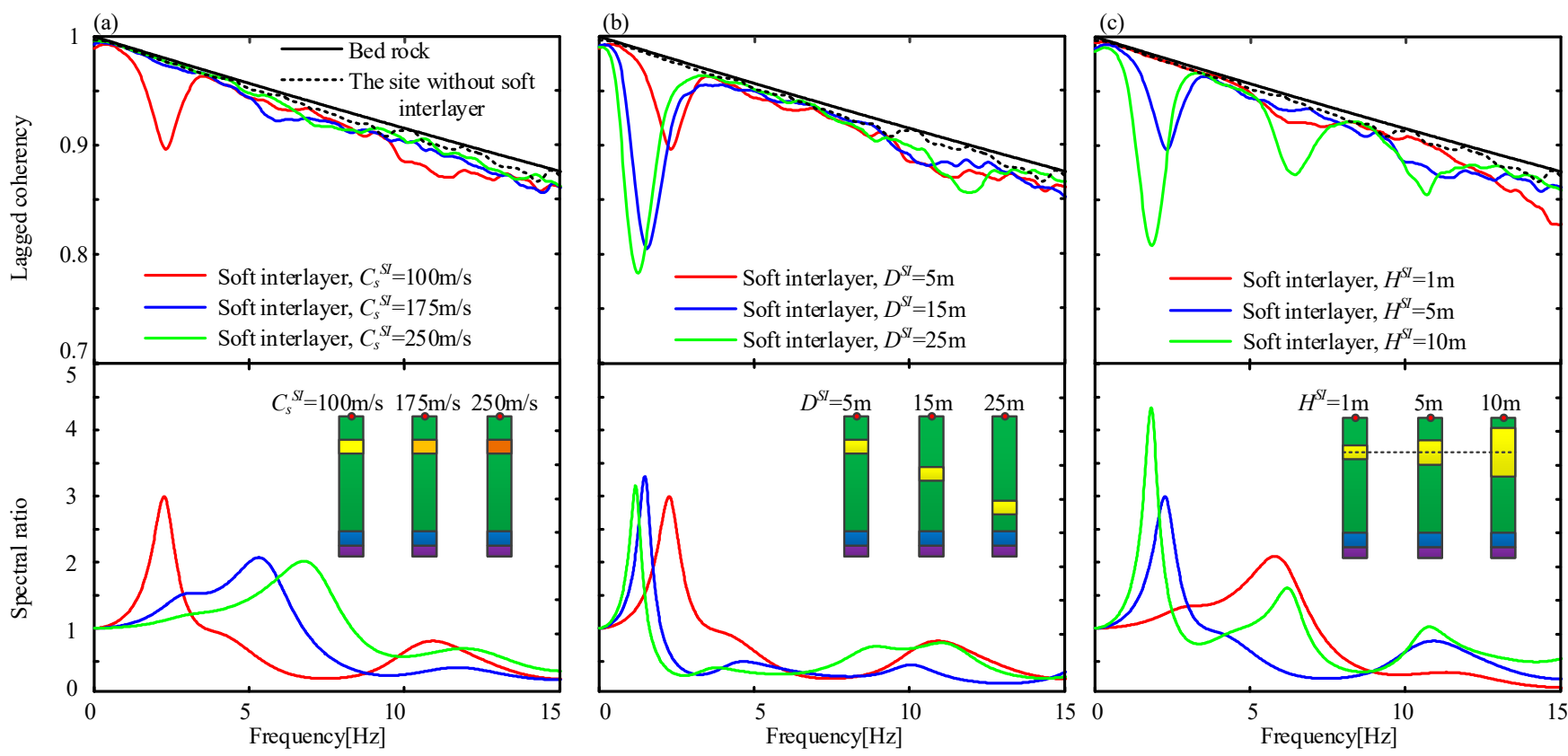

Figure 5. Mean lagged coherency between horizontal in-plane motions and corresponding spectral ratios for varying (a) shear wave velocity; (b) buried depth; and (c) thickness of interlayer. 

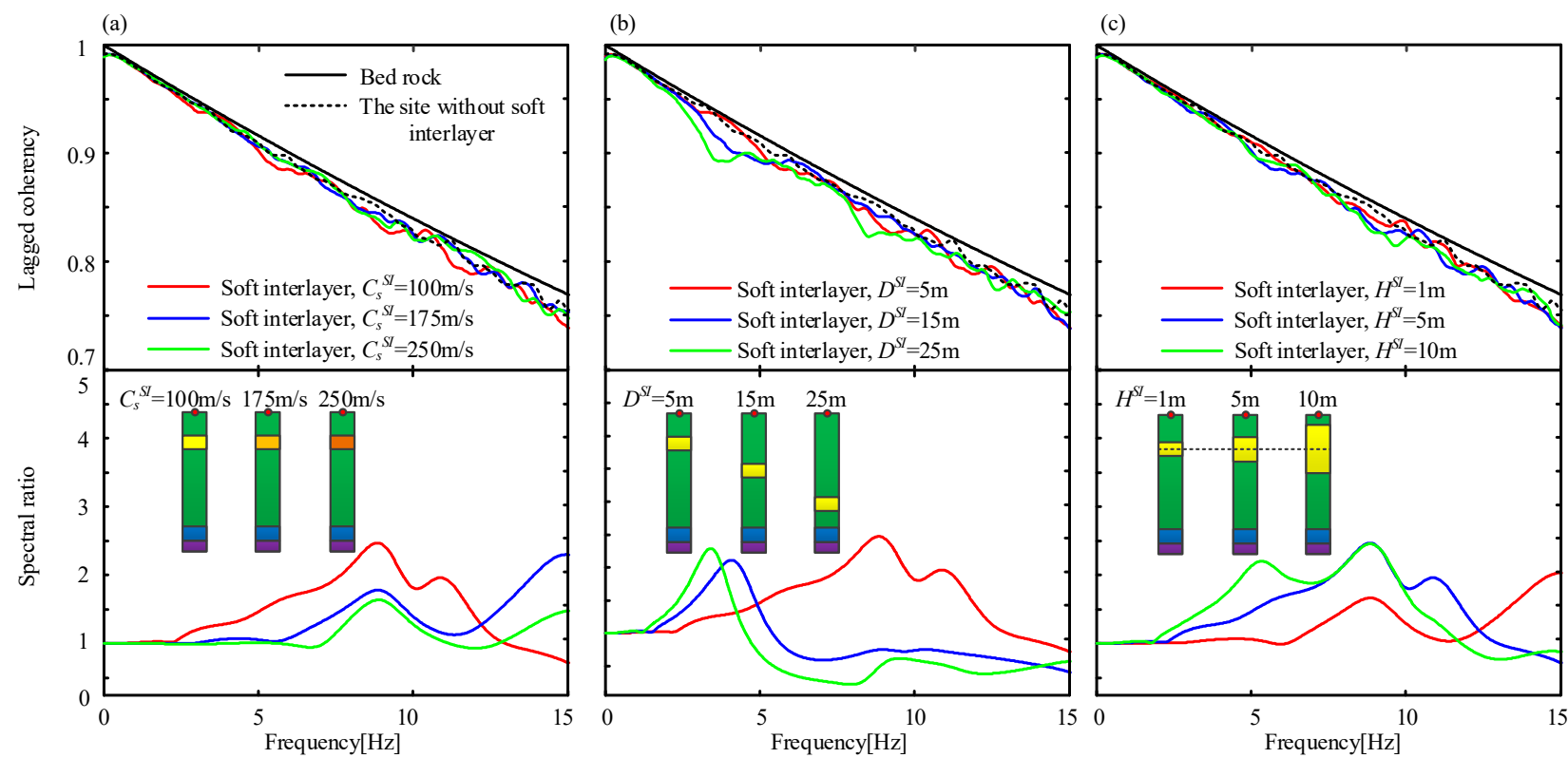

Figure 6. Mean lagged coherency between vertical in-plane motions and corresponding spectral ratios for varying (a) shear wave velocity; (b) buried depth; and (c) thickness of interlayer.

In the cases with buried depth, spatial coherency is more likely to dramatically decrease in long period range in general, which is different from the results for the cases with shear wave velocity and thickness to some extent. With varying buried depth and certain shear wave velocity and thickness, the soft interlayer always amplifies the motion in lower frequency range, while attenuating the motion in higher frequency range. In other words, obvious pikes of modulus of spectral ratio that are larger than 1 always appear in lower frequency range for the case with buried depth, indicating that in lower frequency range the transfer functions at sites $j$ and $k$ present more remarkable difference. By contrast, in the cases with shear wave velocity and thickness, the peaks of spectral ratios tend to more "scattered" or "discrete". Thus, the reduction of lagged spatial coherency caused by varying buried depth may be more inclined to concentrate in the lower frequency range than that caused by shear wave velocity or thickness. In comparison with horizontal motions, the reduction of spatial coherency for vertical motion is much smaller. This may be because that the wave length of $\mathrm{P}$-wave is much longer, and thus $\mathrm{P}$-wave is less sensitive to the soft interlayer.

\section{Numerical Example 2: Non-Linear Soil Behavior}

\subsection{Setup of the Numerical Example}

The site with local soft interlayer shown in Figure $1 \mathrm{~b}$ is still utilized in this example, and non-linear soil behavior (time-varying shear modulus and damping ratio) is considered for each soil layer and the soft interlayer by using the Davidenkov non-linear visco-elastic dynamic constitutive model (taking modulus reduction, damping ratio increase, and irreversible plastic deformations into account) in the numerical site response analysis (detail information about this model can be found in Ref. [52]). To give a general evaluation on the difference between linear soil and non-linear soil cases, varying PGAs of input motion are also considered besides shear wave velocity, buried depth, and thickness of soft interlayer as shown in Table 2. To illustrate, the derived time-varying shear modulus for soft interlayer and soil layers 1 and 2 corresponding to PGA $=0.3 \mathrm{~g}$ are shown in Figure 7; a set of time-varying transfer functions and simulated ground motions in horizontal out-ofplane, horizontal in-plane, and vertical in-plane directions are plotted in Figures 8 and 9, respectively. 
Table 2. Study cases performed.

\begin{tabular}{ccccc}
\hline Item & $\begin{array}{c}\text { The Case with Shear } \\
\text { Wave Velocity }\end{array}$ & $\begin{array}{c}\text { The Case with } \\
\text { Buried Depth }\end{array}$ & $\begin{array}{c}\text { The Case with } \\
\text { Thickness }\end{array}$ & $\begin{array}{c}\text { The Case with } \\
\text { PGA }\end{array}$ \\
\hline$C_{S} S I$ & $100 / 175 / 250 \mathrm{~m} / \mathrm{s}$ & $100 \mathrm{~m} / \mathrm{s}$ & $100 \mathrm{~m} / \mathrm{s}$ & $100 \mathrm{~m} / \mathrm{s}$ \\
$H^{S I}$ & $5 \mathrm{~m}$ & $5 \mathrm{~m}$ & $1 / 5 / 10 \mathrm{~m}$ & $5 \mathrm{~m}$ \\
$D^{S I}$ & $5 \mathrm{~m}$ & $5 / 15 / 25 \mathrm{~m}$ & $7 / 5 / 2.5 \mathrm{~m}$ & $5 \mathrm{~m}$ \\
PGA & $0.3 \mathrm{~g}$ & $0.3 \mathrm{~g}$ & $0.3 \mathrm{~g}$ & $0.1 / 0.2 / 0.3 \mathrm{~g}$ \\
\hline Incident angle & $60^{\circ}$ for SH-wave, $75.4^{\circ}$ for SV-wave, and $60^{\circ}$ for P-wave \\
\hline
\end{tabular}
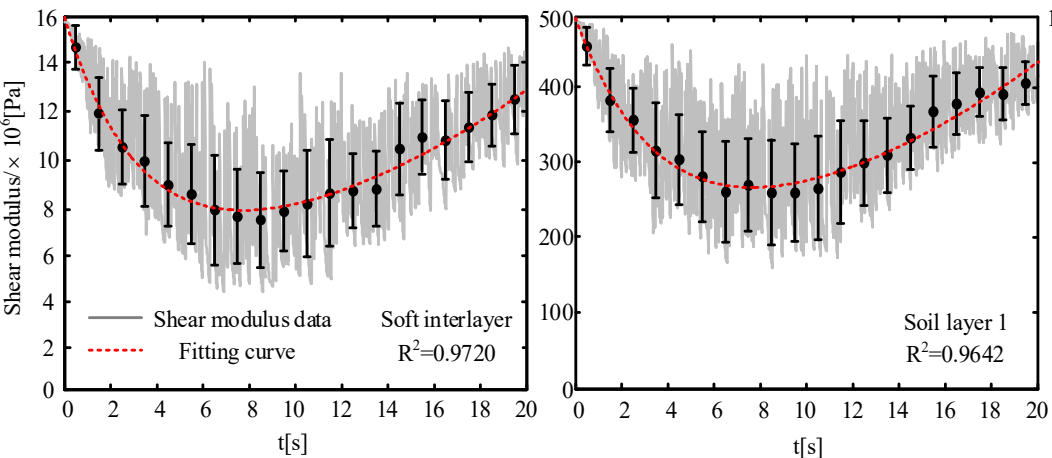

$\mathrm{t}[\mathrm{s}]$

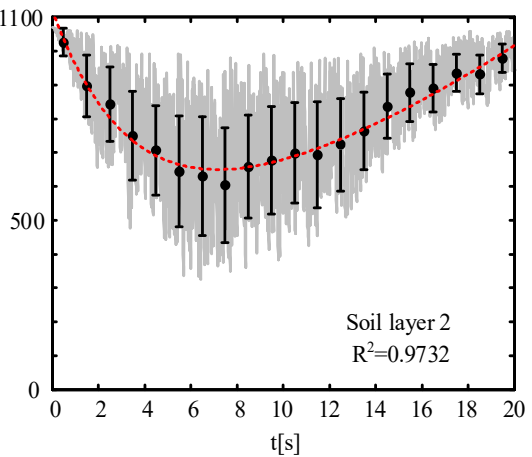

$\mathrm{t}[\mathrm{s}]$

Figure 7. Shear modulus time-histories of various soils.
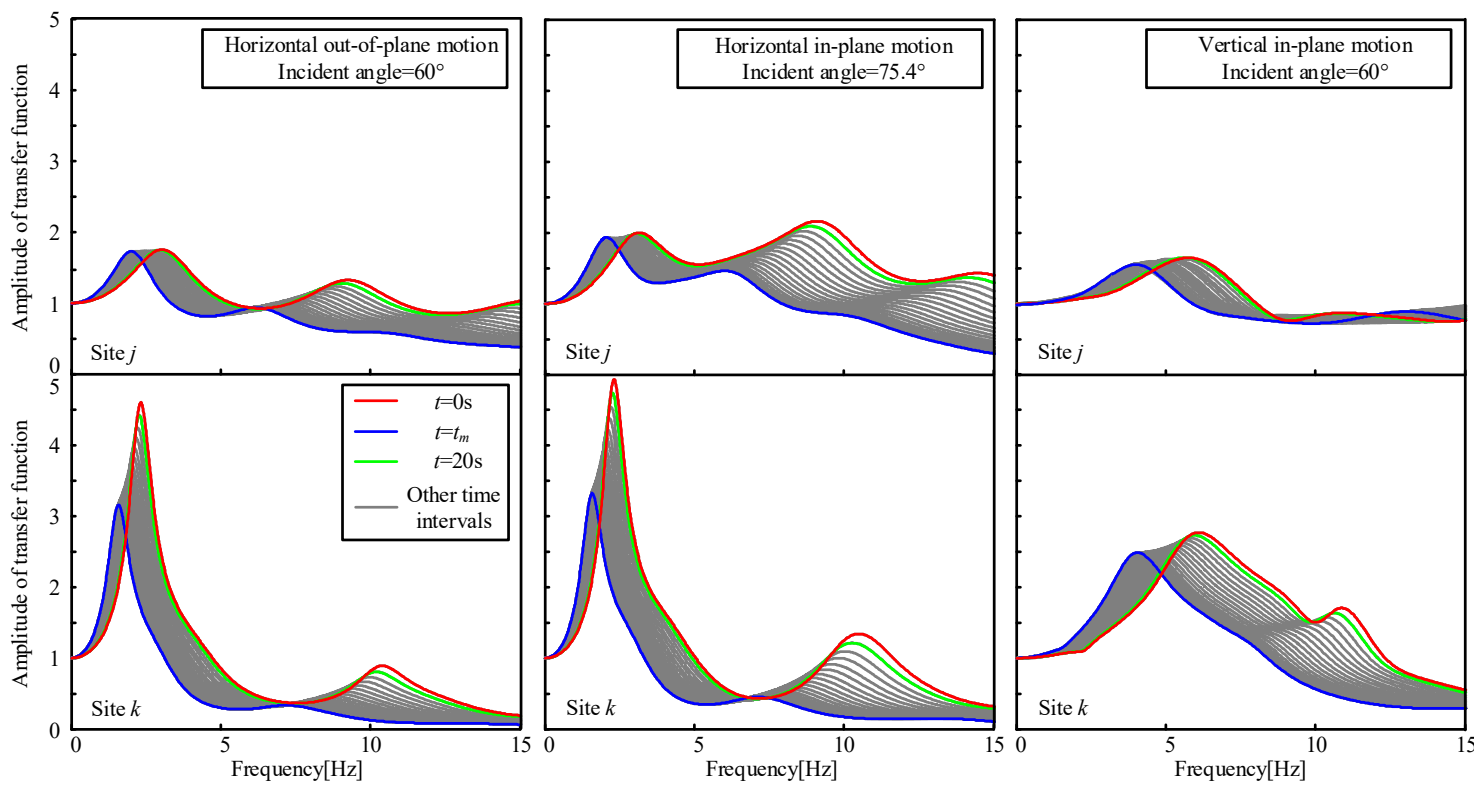

Figure 8. Time-varying transfer functions at sites $\mathrm{j}$ and $\mathrm{k}$ when $C s^{S I}=100 \mathrm{~m} / \mathrm{s}, D^{S I}=5 \mathrm{~m}$, and $H^{S I}=$ $5 \mathrm{~m}$. (Note that $\mathrm{tm}$ is the time interval with respect to the lowest value of shear modulus).
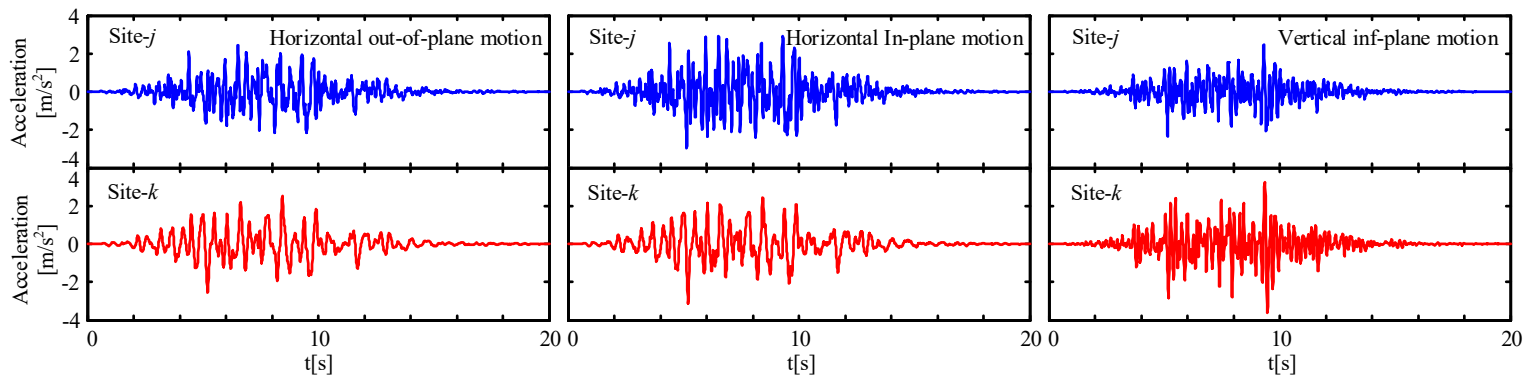

Figure 9. Simulated ground motions when $C_{S}{ }^{S I}=100 \mathrm{~m} / \mathrm{s}, D^{S I}=5 \mathrm{~m}$, and $H^{S I}=5 \mathrm{~m}$. 


\subsection{Results and Discussion}

Mean lagged spatial coherencies for non-linear soil and linear soil cases and corresponding time-varying spectral ratios under varying shear wave velocity of soft interlayer are shown in Figure 10, and $t_{\mathrm{m}}$ is the time interval with respect to the lowest value of shear modulus. As a matter of fact, spectral ratio reflects the difference between the transfer functions at sites $j$ and $k$, and the obvious peaks and troughs in the coherency function of surface ground motions are related to the spectral ratio $[19,26]$. Note that the spectral ratio at $t=0$ is just the one under the linear soil case. Besides, the obvious peaks of spectral ratio are marked with black dashed lines crossing the top and the bottom figures to highlight the respective relation between the peaks of spectral ratio and the troughs of spatial coherency. The frequency points corresponding to the peaks of spectral ratio curve at $t=0$ are numbered with $f_{l}^{x}(x=1,2, \ldots)$, whereas those corresponding to the peaks of spectral ratio curve at $t=t_{m}$ are numbered with $f_{n}{ }^{x}(x=1,2, \ldots)$. For varying buried depth and thickness of soft interlayer and varying PGA of input motion, the lagged spatial coherencies and corresponding time-varying spectral ratios are plotted in Figures 11-13, respectively. Figures 10-12 exhibit the same trend of spatial coherency with respect to varying parameters of soft interlayer, while Figure 13 shows that the difference of spatial coherency functions between linear soil and non-linear soil cases tends to be greater as the input PGA increases. This is because that larger PGA causes more significant non-linearity of soil and thus greater difference of frequency content of motions at sites $j$ and $k$ for non-linear soil case than that for linear soil case.

In general, the curves of lagged spatial coherencies of SVEGMs for the cases with non-linear soil and linear soil are both lower than the curves for the base rock motions. In all study cases, the reduction of spatial coherency for the vertical motion under non-linear soil behavior is only slightly larger than that under linear soil behavior, which indicates that the influence of non-linear soil behavior may be mild for the vertical in-plane wave possessing large wavelength.

For horizontal motion, more importantly, the lagged spatial coherency under nonlinear soil case presents more obvious and larger reduction than that under linear soil case. This indicates that the difference between horizontal ground motions at sites $\mathrm{j}$ and $\mathrm{k}$ under non-linear soil case tends to be greater than that under linear soil case, because, as above mentioned, the spatial coherency measures the similarity between ground motions at two different locations. Due to the existence of soft soil interlayer at site $k$, the amplitude and vibration frequencies of transfer functions at site $\mathrm{j}$ and $\mathrm{k}$ are different at the initial time, and under the linear soil case, the lagged spatial coherencies present obvious reduction at $f_{l}{ }^{x}$. Under non-linear soil case, both the transfer functions at sites $\mathrm{j}$ and $\mathrm{k}$ are time-varying, but the variation trends with time are different for these two sites: (i) The peak amplitude of transfer function at site $\mathrm{k}$ stands greater variation due to the non-linear soft interlayer, not to mention the square amplitude of transfer function (it is the square amplitude of transfer function that is used to simulate SVEGMs); (ii) the variation ranges of frequencies corresponding to peaks are also different, which leads to that the remarkable difference of frequency content between ground motions at sites $j$ and $k$ under non-linear state shows up at more frequency points than that under linear soil state. So, the reduction of spatial coherency under the condition of non-linear soil is more obvious.

Vibration frequency of high order attenuates faster than that of low order, i.e., $\left(f_{l}{ }^{x}-\right.$ $\left.f_{n}{ }^{x}\right)>\left(f_{l}{ }^{x-1}-f_{n}{ }^{x-1}\right)$, which may aggravate the difference of variation process of transfer functions between sites $\mathrm{j}$ and $\mathrm{k}$ and thus the frequency content of ground motions in higher frequency range. Therefore, the reduction of spatial coherency in higher frequency range might be larger than that in lower frequency range. In the meantime, when shear wave velocity of soft interlayer is lower or input PGA is higher, the difference of variation process of transfer functions between site $\mathrm{j}$ and $\mathrm{k}$ would also be more considerable, because the property variation of soft interlayer at site $k$ is more severe than surrounding soil especially for lower stiffness of interlayer and/or higher PGA. 

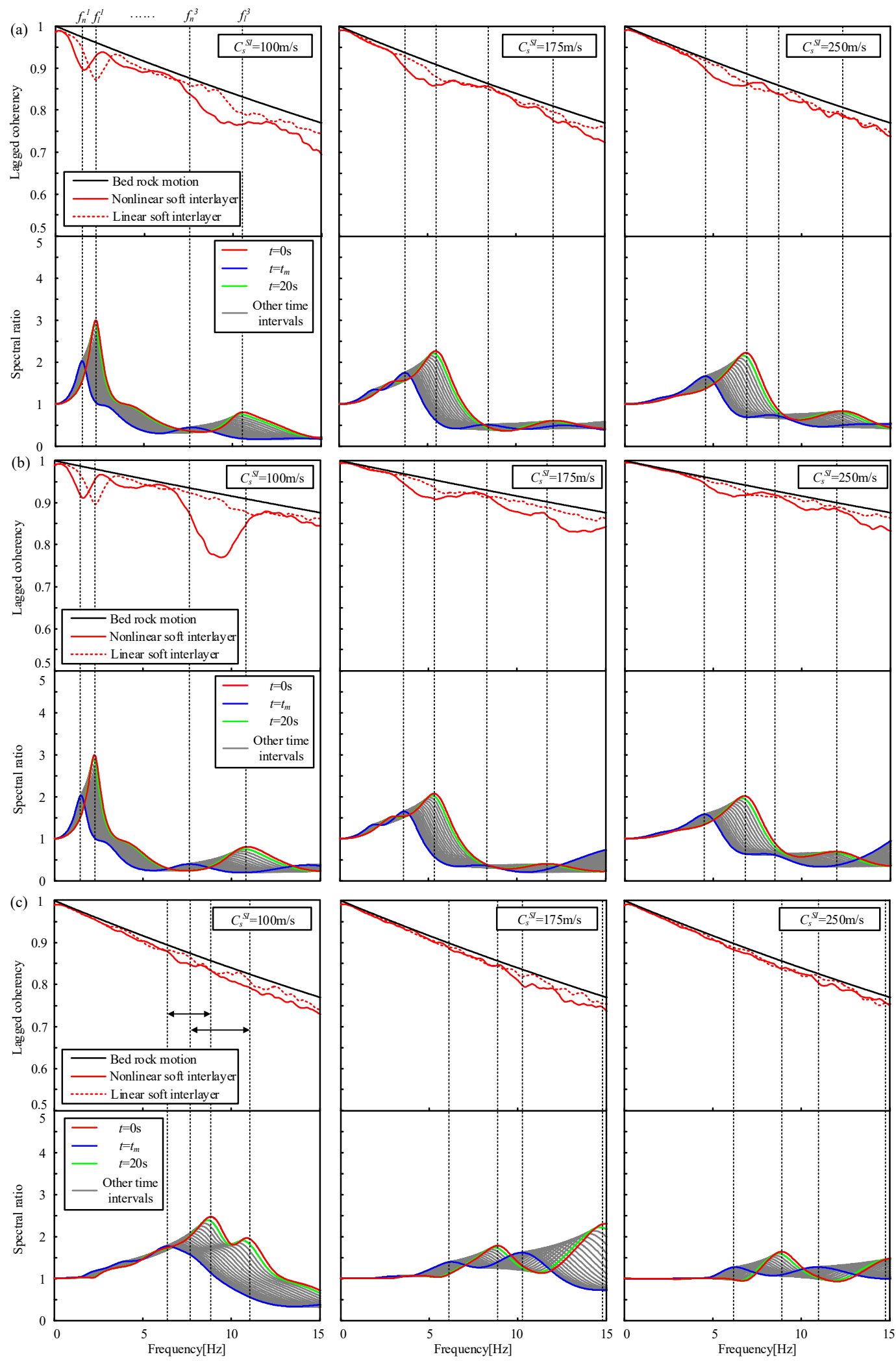

Figure 10. Mean lagged coherency and spectral ratios for (a) horizontal out-of-plane motions; (b) horizontal in-plane motions; and (c) vertical in-plane motions under varying shear wave velocity of soft interlayer. 
(a)

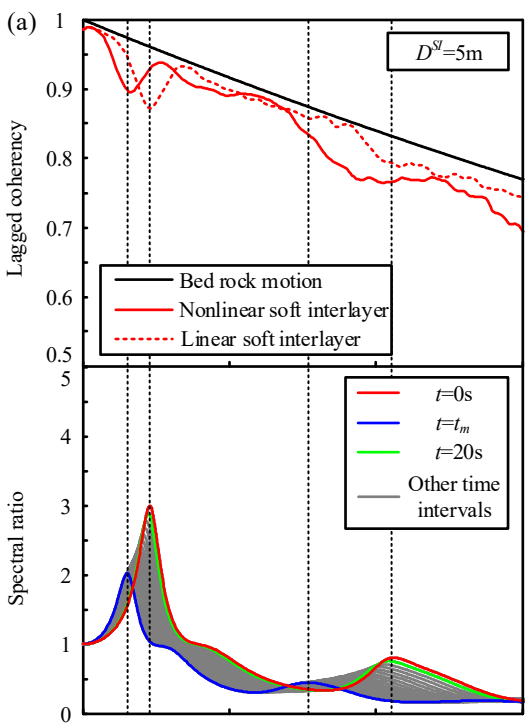

(b)

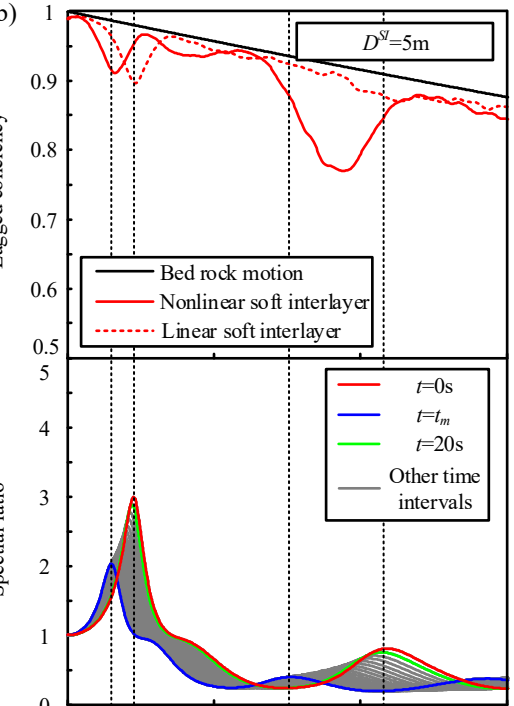

(c)

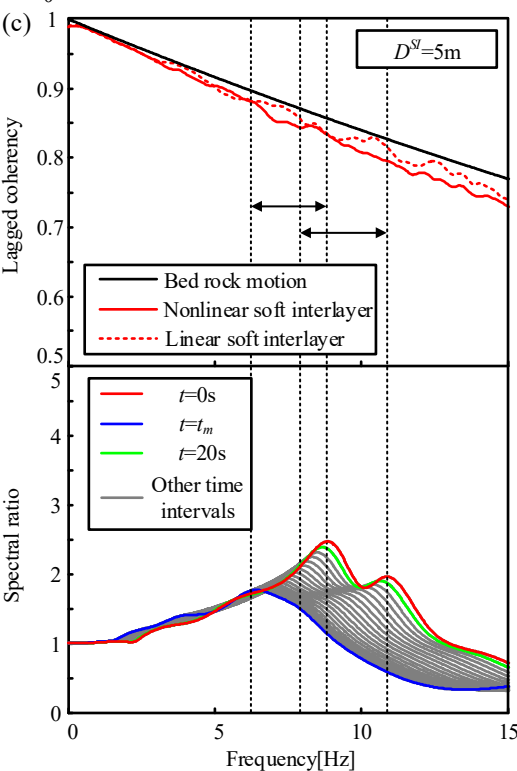

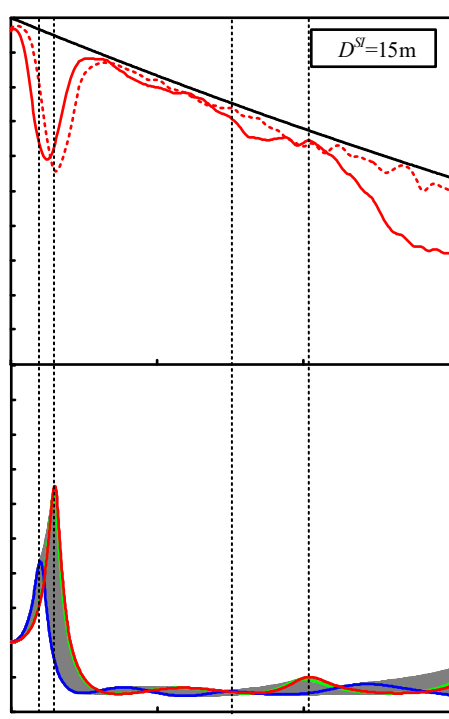
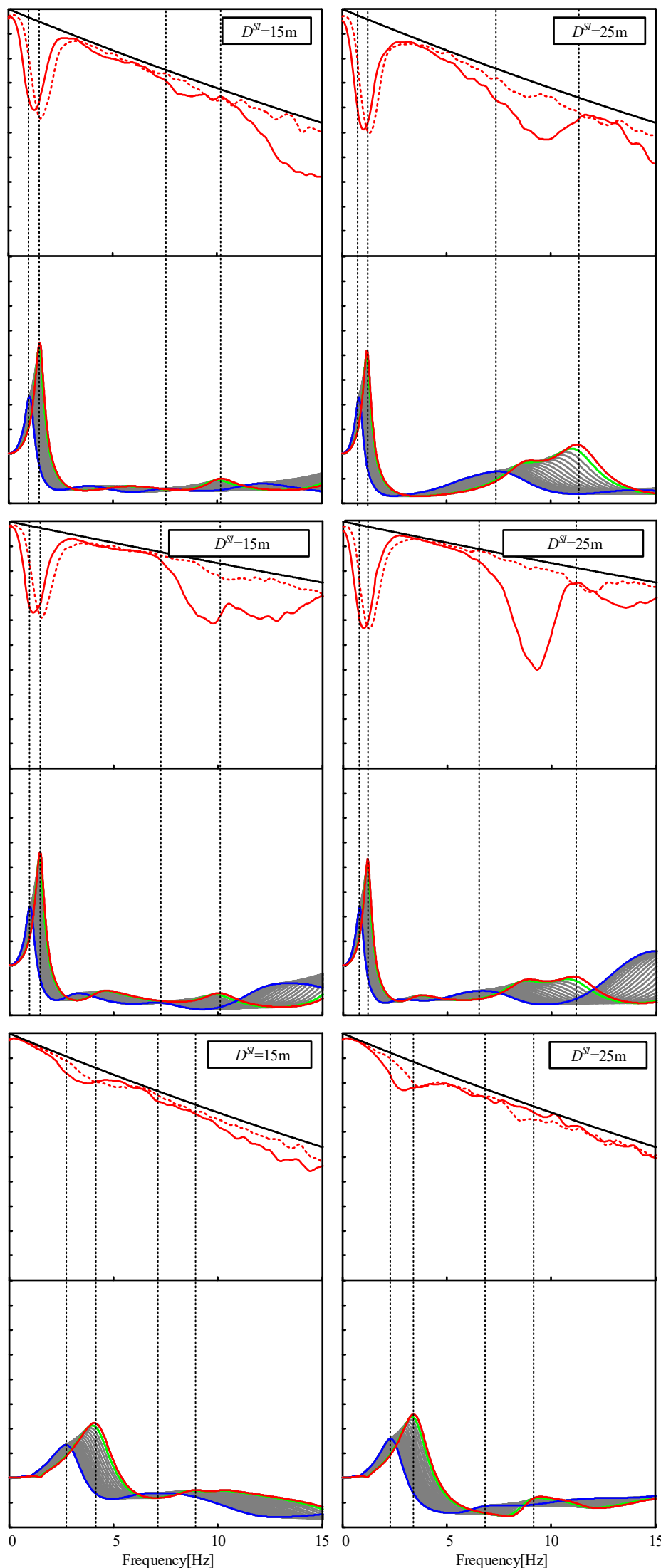

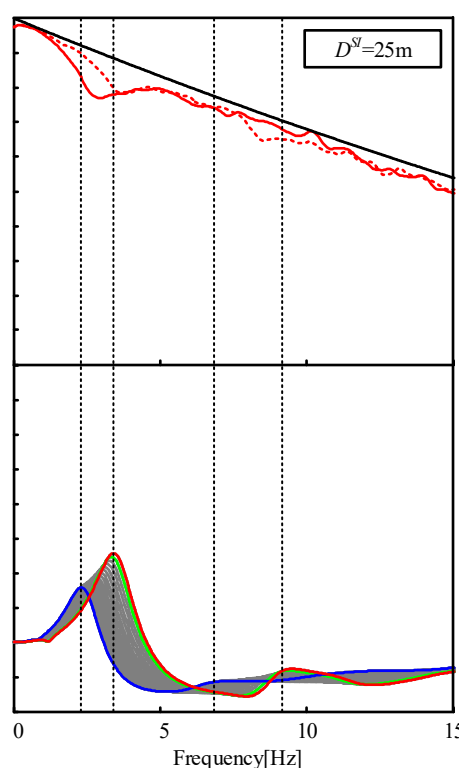

Figure 11. Mean lagged coherency and corresponding time-varying spectral ratios for (a) horizontal out-of-plane motions; (b) horizontal in-plane motions; and (c) vertical in-plane motions under varying buried depth of soft interlayer. 

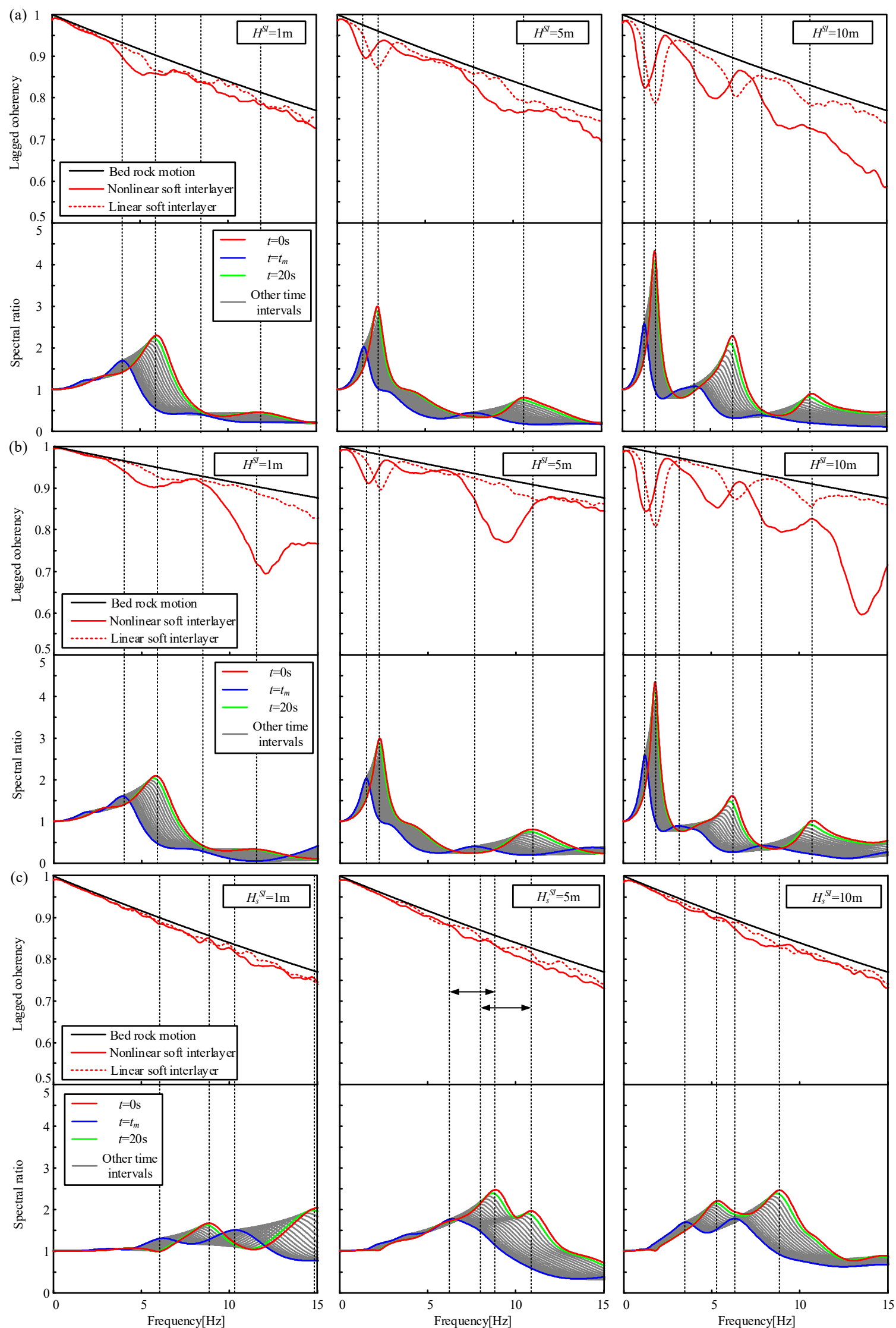

Figure 12. Mean lagged coherency and corresponding time-varying spectral ratios for (a) horizontal out-of-plane motions; (b) horizontal in-plane motions; and (c) vertical in-plane motions under varying thickness of soft interlayer. 

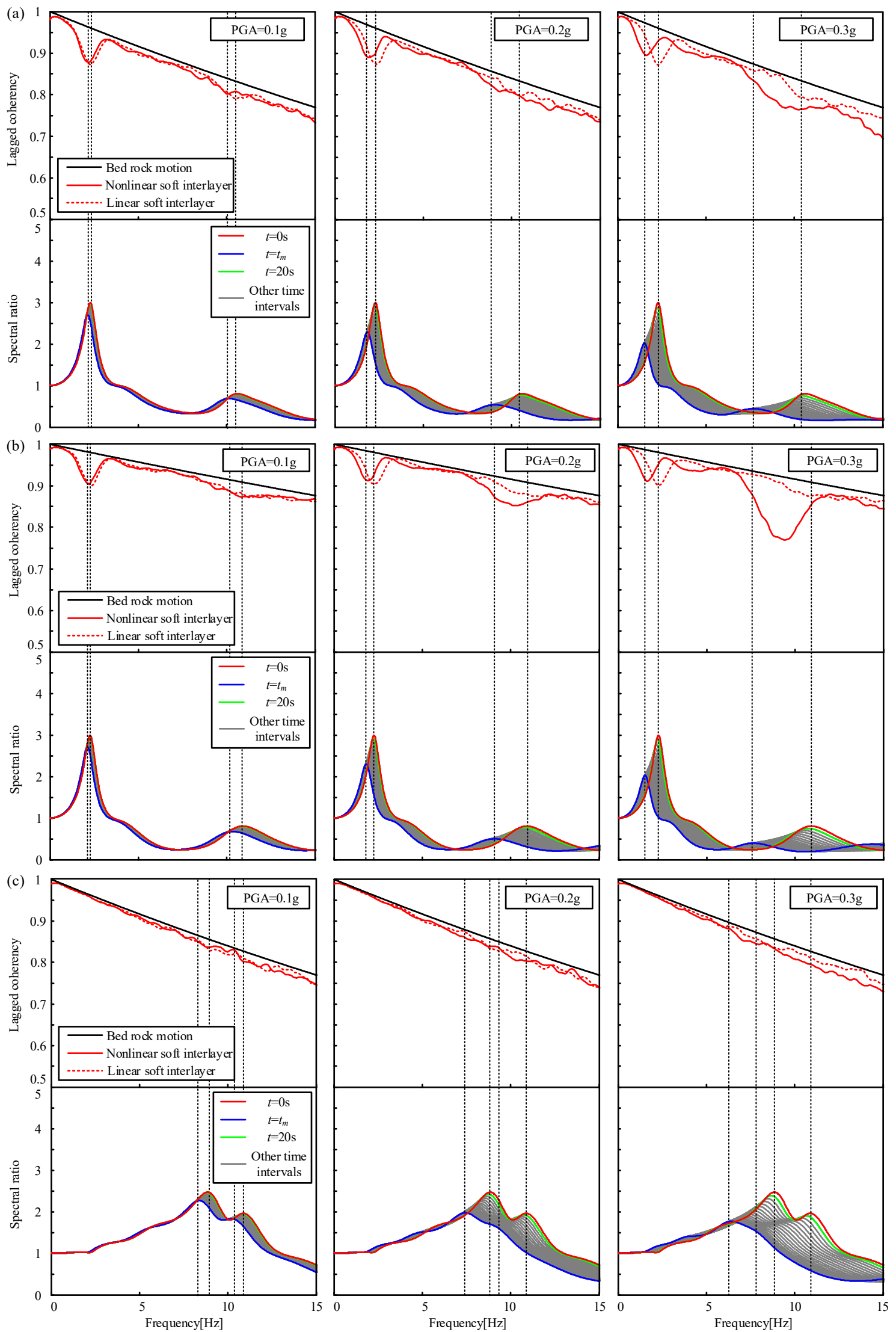

Figure 13. Mean lagged coherency and corresponding time-varying spectral ratios for (a) horizontal out-of-plane motions; (b) horizontal in-plane motions; and (c) vertical in-plane motions under varying PGA of input motion. 
Moreover, the troughs of spatial coherency curve under linear soil case are approximately corresponding to $f_{l}^{x}$, while those under non-linear soil case are inclined to locate between $f_{n}{ }^{x}$ and $f_{l}^{x}$. During earthquake, the growth of input motion amplitude weakens the status of non-linear soil, but as the amplitude of input motion decreases, the soil properties nearly recover to the initial state. Correspondingly, the transfer functions at sites $\mathrm{j}$ and $\mathrm{k}$ move toward lower frequency and amplitude first and then recover, when non-linear soil behavior is considered. In average sense, the general state of soil is between "the best" $\left(t=t_{0}\right)$ and "the worst" $\left(t=t_{m}\right)$ states under non-linear soil case. From another perspective, as above mentioned, the variation ranges of vibration frequencies of transfer functions at sites $\mathrm{j}$ and $\mathrm{k}$ are different. This causes that, in the frequency range of $f_{l}^{x}-f_{n}{ }^{x}$, the frequency contents between ground motions at sites $\mathrm{j}$ and $\mathrm{k}$ are significantly different. So, the obvious troughs of spatial coherency under non-linear soil case are located in the range of $f_{n}{ }^{x} \sim f_{l}^{x}$. In other words, the troughs of spatial coherency under non-linear soil case are not corresponding to $f_{n}{ }^{x}$ or $f_{l}^{x}$.

\section{Conclusions}

By using two numerical examples and based on previously established time-varying transfer function model incorporating the influence of soil non-linearity, the influence regularity of the properties of soft soil interlayer on the lagged spatial coherency between spatially varying earthquake ground motions was studied in the present paper, where the variation trend of lagged coherency loss with the shear wave velocity, thickness, and burial depth of soft soil interlayer was mainly focused on and relevant analyses were presented. The difference of spatial coherency characteristics between linear elastic soil and non-linear soil cases was generally evaluated, and the reason why the difference showed up is given. Some important conclusions are drawn:

(i) As the shear wave velocity of interlayer declines and as the buried depth and thickness increase, remarkable reduction of spatial coherency shows up;

(ii) The reduction of lagged spatial coherency caused by varying buried depth may be more inclined to concentrate in the lower frequency range;

(iii) The non-linear soil behavior can cause greater further reduction of lagged spatial coherency in comparison with linear soil behavior, especially in the higher frequency range;

(iv) The troughs of lagged spatial coherency curve tend to be located in the variation range of vibration frequency of time-varying spectral ratio.

Due to the further reduction of spatial coherency resulted from the existence of soft interlayer and non-linear soil behavior, the cross correlation between spatially varying earthquake ground motions on sites $\mathrm{j}$ and $\mathrm{k}$ may be lower and thus greater randomness of simulated ground motions might appear. Therefore, the local seismic responses of largescale structures might present larger differences, which may cause more severe damage to structures. The results of the present paper shed light on the influence regularity of local soft soil interlayer on the spatial coherency between spatially varying earthquake ground motions so as to facilitate the simulation of seismic motions on a site containing local soft soil interlayer and to thoroughly study the effect of local soft soil interlayer on the seismic response of extended structures. Besides, to some extent, this research provides reference for further study in this field.

Author Contributions: Conceptualization, E.Y.; Data curation, L.Y.; methodology, E.Y.; software, E.Y.; validation, W.L.; writing-original draft preparation, E.Y.; writing-review and editing, Z.Y.; visualization, W.L.; supervision, Y.M.; project administration, Z.Y.; funding acquisition, E.Y., Z.Y. and Y.M. All authors have read and agreed to the published version of the manuscript.

Funding: This research was funded by the National Natural Science Foundation of China (Grant numbers: 51908236, 52109148, 51978304, and 51778260), the China Postdoctoral Science foundation (Grant number: 2019M652649), the Foundation of Hubei Key Laboratory of Blasting Engineering (Grant 
number: BL2021-14), and the Scientific Research Operating Expenses of the Central Government (Grant number: CKSF2021461/YT).

Acknowledgments: This study was financially supported by the National Natural Science Foundation of China (Nos. 51908236, 52109148, 51978304, and 51778260), the China Postdoctoral Science foundation (2019M652649), the Foundation of Hubei Key Laboratory of Blasting Engineering (No. BL2021-14), and the Scientific Research Operating Expenses of the Central Government (No. CKSF2021461/YT). The first author also wants to thank his girlfriend, Yan, for her care.

Conflicts of Interest: The authors declare that they have no conflict of interest.

\section{References}

1. Luco, J.E.; Wong, H.L. Response of a rigid foundation to a spatially random ground motion. Earthq. Eng. Struct. Dyn. 1986, 14, 891-908. [CrossRef]

2. Nazmy, A.S.; Abdel-Ghaffar, A.M. Effects of ground motion spatial variability on the response of cable stayed bridges. Earthq. Eng. Struct. Dyn. 1992, 21, 1-20. [CrossRef]

3. Harichandran, R.S.; Hawwari, A.; Sweidan, B. Response of long span bridges to spatially varying ground motion. J. Struct. Div. 1996, 112, 154-174. [CrossRef]

4. Chen, M.T.; Harichandran, R.S. Response of an earth dam to spatially varying earthquake ground motion. J. Eng. Mech. 2001, 127, 932-939. [CrossRef]

5. Dumanogluid, A.A.; Soyluk, K. A stochastic analysis of long span structures subjected to spatially varying ground motion including the site response effect. Eng. Struct. 2003, 25, 1301-1310. [CrossRef]

6. Soyluk, K. Comparison of random vibration methods for multi-support seismic excitation analysis of long-span bridges. Eng. Struct. 2004, 26, 1573-1583. [CrossRef]

7. Saxena, V.; Deodatis, G.; Shinozuka, M. Effect of spatial variation of earthquake ground motion on the nonlinear dynamic response of highway bridges. In Proceedings of the 12th World Conference on Earthquake Engineering, Auckland, New Zealand, 30 January-4 February 2000.

8. Chopra, A.K.; Wang, J.T. Earthquake response of arch dams to spatially varying ground motion. Earthq. Eng. Struct. Dyn. 2010, 39, 887-906. [CrossRef]

9. Bi, K.M.; Hao, H. Numerical simulation of pounding damage to bridge structures under spatially varying ground motions. Eng. Struct. 2013, 46, 62-76. [CrossRef]

10. Miao, Y.; Yao, E.L.; Ruan, B.; Zhuang, H. Seismic response of shield tunnel subjected to spatially varying earthquake ground motions. Tunn. Undergr. Space Technol. 2018, 77, 216-226. [CrossRef]

11. Zucca, M.; Crespi, P.; Tropeano, G.; Simoncelli, M. On the Influence of Shallow Underground Structures in the Evaluation of the Seismic Signals. Ing. Sismica 2021, 38, 23-35.

12. Zhang, N.; Zhang, Y.; Gao, Y.F.; Pak, R.Y.S.; Yang, J. Site amplification effects of a radially multi-layered semi-cylindrical canyon on seismic response of an earth and rockfill dam. Soil Dyn. Earthq. Eng. 2019, 1161, 145-163. [CrossRef]

13. Zhang, N.; Zhang, Y.; Gao, Y.F.; Pak, R.Y.S.; Yang, J. An exact solution for SH-wave scattering by a radially multi-layered inhomogeneous semi-cylindrical canyon. Geophys. J. Int. 2019, 2172, 1232-1260. [CrossRef]

14. Yao, E.L.; Miao, Y.; Wang, S.Y.; Long, X.H. Simulation of fully nonstationary spatially variable ground motions on a canyon site. Soil Dyn. Earthq. Eng. 2018, 115, 198-204. [CrossRef]

15. Harichandran, R.S.; Vanmarcke, E.H. Stochastic variation of earthquake ground motion in space and time. J. Eng. Mech. 1986, 1138, 1271-1273. [CrossRef]

16. Shinozuka, M.; Deodatis, G. Stochastic process models of earthquake ground motion. J. Probab. Eng. Mech. 1988, 33, 114-123. [CrossRef]

17. Hao, H.; Oliveira, C.S.; Penzien, J. Multiple-station ground motion processing and simulation based on SMART-1 array date. Nucl. Eng. Des. 1989, 1113, 293-310. [CrossRef]

18. Deodatis, G. Non-stationary stochastic vector processes: Seismic ground motion applications. Probabilistic Eng. Mech. 1996, 113, 149-167. [CrossRef]

19. Zhang, D.Y.; Xie, W.C.; Pandey, M.D. Synthesis of spatially correlated ground motions at varying sites based on Vector-valued Seismic Hazard Deaggregation. Soil Dyn. Earthq. Eng. 2012, 418, 1-13. [CrossRef]

20. Miao, Y.; Yao, E.; Ruan, B.; Zhuang, H.; Chen, G.; Long, X. Improved hilbert spectral representation method and its application to seismic analysis of shield tunnel subjected to spatially correlated ground motions. Soil Dyn. Earthq. Eng. 2018, 111, 119-130. [CrossRef]

21. Wu, Y.X.; Gao, Y.F.; Zhang, N.; Li, D. Simulation of Spatially Varying Ground Motions in V-shaped Symmetric Canyons. J. Earthq. Eng. 2016, 206, 1-19. [CrossRef]

22. Wu, Y.X.; Gao, Y.F.; Zhang, N.; Li, D. Simulation of Spatially Varying Non-Gaussian and Nonstationary Seismic Ground Motions by the Spectral Representation Method. J. Eng. Mech. 2018, 1441, 04017143. [CrossRef]

23. Wu, Y.X.; Gao, Y.F. A modified spectral representation method to simulate non-Gaussian random vector process considering wave-passage effect. Eng. Struct. 2019, 201, 109587. [CrossRef] 
24. Wu, Y.X.; Gao, Y.F.; Zhang, L.M.; Jang, Y. How the distribution characteristics of soil property affect probabilistic foundation settlement: From the view of the first four statistical moments. Can. Geotech. J. 2020, 574, 595-607. [CrossRef]

25. Sarkar, K.; Gupta, V.K.; George, R.C. Wavelet-based generation of spatially correlated accelerograms. Soil Dyn. Earthq. Eng. 2016, 87, 116-124. [CrossRef]

26. Bi, K.M.; Hao, H. Influences of irregular topography and random soil properties on coherency loss of spatial seismic ground motions. Earthq. Eng. Struct. Dyn. 2011, 409, 1045-1061. [CrossRef]

27. Ancheta, T.D.; Stewart, J.P.; Abrahamson, N.A. Engineering characterization of earthquake ground motion coherency and amplitude variablity. In Proceedings of the 4th International IASPEI Symposium on Effects of Surface Geology on Seismic Motion 2011, Santa Barbara, CA, USA, 23-26 August 2011.

28. Abrahamson, N.A.; Bolt, B.A.; Darragh, R.B.; Penzien, J.; Tsai, Y.B. The SMART I Accelerograph Array 1980-1987, A Review. Earthq. Spectra 1987, 32, 263-287. [CrossRef]

29. Abrahamson, N.A.; Schneider, J.F.; Stepp, J.C. Empirical Spatial Coherency Functions for Application to Soil-Structure Interaction Analyses. Earthq. Spectra 1991, 7, 1-27. [CrossRef]

30. Abrahamson, N. Program on Technology Innovation: Spatial Coherency Models for Soil-Structure Interaction; EPRI: Palo Alto, CA, USA; U.S. Department of Energy: Germantown, MD, USA, 2007.

31. Abrahamson, N. Program on Technology Innovation: Effects of Spatial Incoherence on Seismic Ground Motions; Report No. EPRI 1015110 2006; ERPI: Palo Alto, CA, USA, 2006.

32. Konakli, K.; Dreger, D.; Der Kiureghian, A. Coherency analysis of accelerograms recorded by the UPSAR array during the 2004 Parkfield earthquake. Earthq. Eng. Struct. Dyn. 2014, 43, 641-659. [CrossRef]

33. Imtiaz, A.; Cornou, C.; Bard, P.Y.; Zerva, A. Effects of site geometry on short-distance spatial coherency in Argostoli, Greece. Bull. Earthq. Eng. 2018, 165, 1801-1827. [CrossRef]

34. Der Kiureghian, A. A coherency model for spatially varying ground motions. Earthq. Eng. Struct. Dyn. 1996, $251,99-111$. [CrossRef]

35. Somerville, P.G.; McLaren, J.P.; Sen, M.K.; Helmberger, D.V. The influence of site conditions on the spatial incoherence of ground motions. Struct. Saf. 1991, 101, 1-13. [CrossRef]

36. Lou, L.; Zerva, A. Effects of spatially variable ground motions on the seismic response of a skewed, multi-span, RC-highway bridge. Soil Dyn. Earthq. Eng. 2005, 25, 729-740. [CrossRef]

37. Liao, S.; Zerva, A.; Stephenson, W.R. Seismic spatial coherency at a site with irregular subsurface topography. In Probabilistic Applications in Geotechnical Engineering; ASCE: Reston, VA, USA, 2007.

38. Bi, K.M.; Hao, H. Modelling and simulation of spatially varying earthquake ground motions at sites with varying conditions. Probabilistic Eng. Mech. 2012, 29, 92-104. [CrossRef]

39. Liang, J.W.; Liu, Z.X.; Huang, L.; Guogang, Y. The indirect boundary integral equation method for the broadband scattering of plane P, SV and Rayleigh waves by a hill topography. Eng. Anal. Bound. Elem. 2019, 98, 184-202. [CrossRef]

40. Huang, L.; Liu, Z.X.; Wu, C.; Liang, J. The scattering of plane P, SV waves by twin lining tunnels with imperfect interfaces embedded in an elastic half-space. Tunn. Undergr. Space Technol. 2019, 85, 319-330. [CrossRef]

41. Takahashi, N.; Hyodo, M.; Hyde, A.F.L.; Yamamoto, Y.; Kimura, S. Online earthquake response test for stratified layers of clay and sand. J. Geotech. Geoenviorn. Eng. 2006, 132, 611-621. [CrossRef]

42. Bilotta, E.; De Santis, L.; Di Laora, R.; D'Onofrio, A.; Silvestri, F. Importance of seismic site response and soil-structure interaction in dynamic behavior of a tall building. Geotechnique 2015, 65, 391-400. [CrossRef]

43. Rayhani, M.H.T.; Asce, S.M.; Naggar, M.H.E.; Asce, M. Numerical modeling of seismic response of rigid foundation on soft soil. Int. J. Geomech. 2008, 86, 336-346. [CrossRef]

44. Field, E.H.; Johnson, P.A.; Beresnev, I.A.; Zeng, Y. Nonlinear ground-motion amplification by sediments during the 1994 Northridge earthquake. Nature 1997, 3906660, 599-602. [CrossRef]

45. Frankel, A.D.; Carver, D.L.; Williams, R.A. Nonlinear and linear site response and basin effects in Seattle for the M 6.8 Nisqually, Washington, earthquake. Bull. Seismol. Soc. Am. 2002, 926, 2090-2109. [CrossRef]

46. Bonilla, L.F.; Archuleta, R.J.; Lavallée, D. Hysteretic and dilatant behavior of cohesionless soils and their effects on nonlinear site response: Field data observations and modeling. Bull. Seismol. Soc. Am. 2005, 956, 2373-2395. [CrossRef]

47. Wu, C.; Peng, Z.; Assimaki, D. Temporal changes in site response associated with the strong ground motion of the 2004 Mw6.6 mid-Niigata earthquake sequences in Japan. Bull. Seismol. Soc. Am. 2009, 996, 3487-3495. [CrossRef]

48. Régnier, J.; Cadet, H.; Bonilla, L.F.; Bertrand, E.; Semblat, J.F. Assessing nonlinear behavior of soils in seismic site response: Statistical analysis on KiK-net strong-motion data. Bull. Seismol. Soc. Am. 2013, 1033, 1750-1770. [CrossRef]

49. Ren, Y.; Wen, R.; Yao, X.; Ji, K. Five parameters for the evaluation of the soil nonlinearity during the Ms8.0 Wenchuan Earthquake using the HVSR method. Earth Planets Space 2017, 691, 116. [CrossRef]

50. Wang, H.Y.; Jiang, W.P.; Wang, S.Y.; Miao, Y. In Situ assessment of soil dynamic parameters for characterizing nonlinear seismic site response using KiK-net vertical array data. Bull. Earthq. Eng. 2019, 175, 2321-2360. [CrossRef]

51. Yao, E.L.; Wang, S.Y.; Ruan, B.; Miao, Y.; Zhu, L.H. Numerical study on site response considering ground motion spatial variation. Soil Dyn. Earthq. Eng. 2019, 127, 105836. [CrossRef]

52. Yao, E.L.; Wang, S.Y.; Miao, Y.; Ye, L.; Zhu, L.H. Simulation of fully non-stationary spatially varying ground motions considering nonlinear soil behavior. Soil Dyn. Earthq. Eng. 2020, 129, 105954. [CrossRef] 
53. Wolf, J.P. Soil-Structure Interaction Analysis in Time Domain; Prentice Hall: Englewood Cliffs, NJ, USA, 1988.

54. Wu, Y.X.; Gao, Y.F.; Li, D.Y. Simulation of spatially correlated earthquake ground motions for engineering purposes. Earthq. Eng. Eng. Vib. 2011, 102, 163-173. [CrossRef]

55. Clough, R.W.; Penzien, J. Dynamics of Structures, 2nd ed.; McGraw Hill: New York, NY, USA, 1993.

56. Seya, H.; Talbott, M.; Hwang, H. Probabilistic seismic analysis of a steel frame structure. Probab. Eng. Mech. 1993, 8, 127-136. [CrossRef]

57. Sobczky, K. Stochastic Wave Propagation; Kluwer Academic Publishers: Dodrecht, The Netherlands, 1991. 